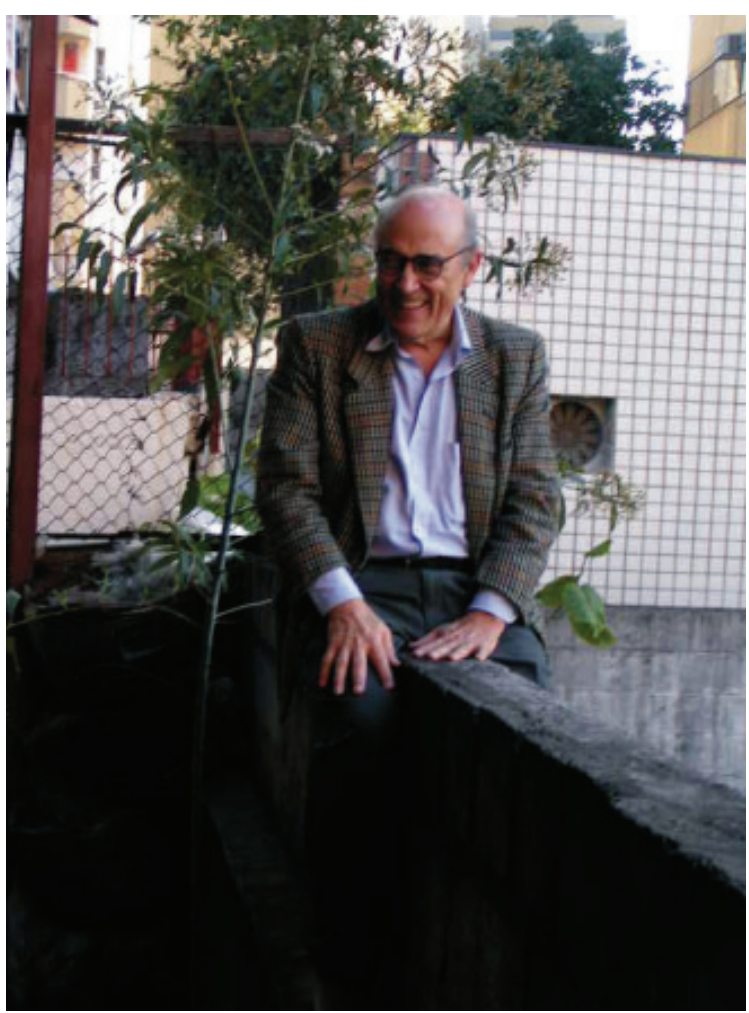

amigo Guedes

Foto do Arquivo Adilson Costa Macedo

\title{
JOAQUIM GUEDES
}

Sylvio Barros Sawaya

Adilson Costa Macedo

Anne Marie Sumner

Carlos Antônio Leite Brandão

Gilberto Belleza

Maria Luisa Trindade Bestetti

Miguel Pereira

Mônica Junqueira de Camargo

Olgária Matos

Paula Katakura 


\section{Mestre joAquim guedes}

Desde seu falecimento, em 27 de julho de 2008, muitas foram as manifestações de reconhecimento da contribuição do arquiteto Joaquim Guedes à cultura brasileira, em especial à arquitetônica. A revista Pós optou por the render o merecido tributo trazendo, neste primeiro número lançado após sua morte, a homenagem da comunidade acadêmica representada por alguns professores e orientandos, os quais, de alguma forma, conviveram mais proximamente com ele nestes últimos tempos. São eles: Sylvio Barros Sawaya, Adilson Costa Macedo, Anne Marie Sumner, Carlos Antônio Leite Brandão, Gilberto Belleza, Maria Luisa Trindade Bestetti, Miguel Pereira, Mônica Junqueira de Camargo, Olgária Matos e Paula Katakura..

\section{Arquiteto johquim guedes}

Tive a oportunidade de ler os textos sentidos e cheios de luz de meus companheiros e amigos nesta tarefa de continuar nossa conserva com o Guedes. Deles recolho elementos básicos de sua trajetória, que passo a enumerar:

Adilson recupera o grande professor e seu método iluminado de conquistar a arquitetura; Anne Marie o coloca como franciscano, palmilhando os espaços deste país e construindo-os na procura da justa e correta medida; Carlos Antonio fala da meditação sobre a vida em diálogo com o tempo da arquitetura como coisa concreta; Gilberto faz referência à criação e feitura inovadora de sua arquitetura, relembrando o momento fundamental dos então jovens Millan e Guedes; Maria Luiza recupera o amor pela cidade, especialmente a de São Paulo e a prática provocativa que o fazia um mestre completo para seus orientandos; Miguel, companheiro inseparável, recupera o grande arquiteto com discurso irreverente e polêmico que, nas pausas, produz textos cuidadosamente elaborados, trazendo contribuições intelectuais 
de valia; Mônica mostra como, a partir de um projeto feito com segurança e precisão, ele foi um grande mestre preocupado com o caminho intelectual do aluno; Olgária diz da "Geometria Habitada", um discurso do método e uma filosofia da construção; geometria é a forma da matéria, é sua alma, uma aula magistral de arquitetura e vida; Paula enfatiza a utilização dos diagramas no desenvolvimento dos projetos, relacionando as formas à vida da sociedade e da cidade, buscando uma arquitetura mais justa.

A tentativa de síntese, mesmo precária e incorreta, traça um perfil bem completo desse grande brasileiro e arquiteto. Não dá para ser redundante diante do que foi apresentado. Sobra-me o testemunho de quem o teve sempre como amigo e mestre, nos tempos de entendimento e nos momentos em que, adversários, sempre fomos lastreados por um grande respeito e afeto que a tudo vencia.

Pude, sendo atualmente diretor da FAU, estar muito próximo no momento seguinte à sua morte. $O$ encontro com os filhos, irmãos, familiares e amigos, com Pedro Taddei, presidente da Fupam, foi muito intenso e daí resultou os dois dias de seu velório na FAU-Maranhão.

Uma despedida longa, com uma emoção profunda perpassando a todos, com o irmão e grande amigo, padre Vicente, orientando-nos na compreensão do significado dessa vida que se apresentava pela ausência diante de nós. Tentei começar este texto na primeira semana de agosto; só agora, decorridos quatro meses de sua morte, é que consigo encadeá-lo, quando o sentimento de perda foi ultrapassado pela importância do que foi feito.

Falar do Guedes é um pouco falar de mim mesmo. Permitam-me relembrar alguns de nossos encontros que se realizam sistematicamente desde 1960, quando fui à Biblioteca Municipal Mario de Andrade, antes de ser aluno da faculdade, para escutá-lo, com a psicóloga Noemi Silveira Rudolfer sobre a profissão de arquiteto. Na saída encontrei-o com Liliana, sua esposa, conversamos e a certeza sobre fazer arquitetura consolidou-se.

Durante o curso de arquitetura, na aula de materiais, fiz uma mesa de madeira colada e moldada como exercício do curso. Terminando o curso, em 1967, com o Pedro Taddei, fomos estagiários e arquitetos recém-formados em seu escritório. Volto à FAU em 1971 como professor de projeto e reencontro o Guedes ainda na tecnologia.

Cursamos o doutorado em 1972, o Guedes passa para planejamento e depois para projeto. Foi quando assisti às suas discussões, às vezes fortes, com os colegas. Dei aulas com o Guedes no quarto ano, por algum tempo, e apoiei-o para chefe do departamento. Exercício rápido na função, mas mesmo assim muito importante pelo seminário internacional que promoveu sobre a arquitetura e o ensino. É após esse período que o Guedes se aposenta da FAU.

Nos anos 90 conversamos muito, sobretudo nas reuniões do Conselho Superior do IAB, quando fui representante brasileiro junto do Conselho Internacional dos Arquitetos de Língua Portuguesa. Conversamos, também, várias vezes durante o processo eleitoral do IAB São Paulo. A última vez que nos falamos foi por telefone, a propósito da cerimônia dos 60 anos da FAU, acontecimento que ele tinha agendado errado e pensava que seria possível ir ainda, mas, na verdade, havia ocorrido uma semana antes. 
Trabalhei com meu grande amigo e mestre, Carlos Millan, em 1964, ano em que faleceu, indo para o escritório do Guedes. Já conhecia bastante do que ambos fizeram juntos enquanto sócios e companheiros em uma mesma sala de trabalho.

Acabei, de alguma maneira, participando, em tempos diferentes, dessa experiência em comum.

A ausência prematura do Millan e o longo trajeto de Guedes não impedem de reconhecer, em ambos, dois pilares básicos da arquitetura aqui em São Paulo. 0 que os unem são, por um lado, uma profunda visão social aliada, e, por outro lado, a um fazer da arquitetura extremamente competente e inovador.

O Millan, a partir de F. L. Wright, Neutra e outros, encontra o Corbusier, faz uma releitura de sua obra, depara-se com o caminho para uma arquitetura despojada, essencial, carregando, em sua realização, um enorme e erudito requinte sublimado.

O Guedes, a partir do Corbusier, encontra o Alvar Aalto e vai contrapor, ao regramento assumido pela moderna arquitetura paulista, uma visão inovadora e instigadora de novas possibilidades, posição que mantém por toda a vida.

No Millan, uma radicalidade construtiva, associada a uma significação essencial dos elementos, propondo a recomposição de universos simbólicos. No Guedes, uma geometria rica que ultrapassa o retangular e apresenta grande riqueza na transição dos materiais que a realizam, absolutamente, perfeita.

O tempo a mais de vida concedido ao Guedes permitiu a aplicação constante de uma inquietação polêmica, sempre contestadora, mas também altamente propositiva. É uma procura incessante dos caminhos corretos, verdadeiros, acirrados sem parar pela interpretação do que vai ocorrendo e do que sinaliza para o futuro no mundo entre nós.

Há uma participação política a partir da condição de arquiteto que tudo discute e contribui. Há uma quase reverência diante da filosofia que mostra uma procura constante do pensar aderido à verdade. Há uma erudição praticada que se traduz em comunicações, palestras e textos os quais deverão ser coligidos e publicados.

A atuação nas atividades de representação profissional, sempre constantes e, muitas vezes, surpreendentes em suas formulações, culminam em uma presença ativa, nestes tempos últimos, no Instituto de Arquitetos do Brasil, com ação incisiva em São Paulo, em que o reconhecimento das novas gerações e de sua energia espalhada por todo o território do estado de São Paulo é a marca fundamental.

Contribui para essa ação sua grande energia, sempre jovem e incansável, permitindo-Ihe lançar pontes entre gerações e propor um futuro para a atuação dos arquitetos. A parada abrupta que o retirou de nosso convívio, deu-se em um momento maior de plenitude pessoal, o que, associado à sua trajetória por toda a vida, fará dele presença constante e instigante para aqueles que continuaram e continuarão na afirmação da arquitetura como parte fundamental da cultura e da vida social neste mundo.

Faltou falar do Artigas, esse grande estruturador de uma escola de arquitetura entre nós e que, dialeticamente, explica mais do que o Niemeyer o percurso trilhado pelo Guedes. Há um contraponto constante entre ambos, lastreado em respeito, amizade e questionamento. Esse nosso grande professor, fundador de escola, o Artigas, constitui-se no instigador maior do Guedes, seja na militância 
política, seja nos percalços das atribulações da ditadura, seja na concreção da arquitetura. Há uma referência constante do Guedes em relação a esse arquiteto maior que Ihe serve de guia. É, no entanto e, sobretudo, nos entendimentos da aula de arquitetura, que esse contraponto surge plenamente. Preocupados ambos com o rigor do pensamento e a compreensão intelectual da arquitetura e de seu fazer, foi, sem dúvida, essa presença maior que levou o Guedes a avançar tanto e tão criativamente no exercício do ensino da arquitetura, ao mesmo tempo contestando e dando continuidade. Esses dois grandes mestres, os quais tivemos a felicidade de ter aqui na FAU, explicam muito do que esta escola se constitui e abrem grandes indagações para saber o que ela poderá ser. Está aí um tema para ser aprofundado em nossas pesquisas.

O fazer da arquitetura em sua realização enquanto construção e forma, que tornam o arquiteto um mestre, como dizia o Guedes, é o ponto central nesta encruzilhada mundializada e dinâmica por que passamos. Encontrar, sendo específico e centrado em sua própria energia, a maneira de inserir-se neste mundo, que fica mais próximo e menor, é a incumbência e a convocação que o Guedes faz a todos nós neste momento.

\section{Sylvio Barros Sawaya}

Professor e diretor da FAUUSP

\section{O AMIgO GUEDES}

Dez anos mais velho do que eu. Fui seu aluno na disciplina Materiais de Construção, funcionário de seu escritório entre 1968 e 1969 e, por volta de 1988 passei a lecionar com ele na FAUUSP, no Departamento de Projeto, no curso de graduação. Em seguida, convidou-se para participar das disciplinas da pósgraduação, sob sua responsabilidade. Quando se aposentou, há seis anos, torneime responsável pelas disciplinas, das quais participa também o professor Dario Montesano. O professor Guedes, mesmo depois de aposentado, continuou com as aulas do curso de pós-graduação.

Para ser admitido em seu escritório fiz uma prova, o projeto de uma casa onde foi dado o terreno e o programa de necessidades. Estava formado há quatro anos, mal conhecia o Guedes, achava ele um bom arquiteto. Tinha como referência uma casa do Pacaembu, que conheci no final da obra quando ele levou um grupo de alunos para visita. Dias depois da prova, chamou-me no escritório, e com meus desenhos na frente, disse: "Gostei! Você estudou criteriosamente cada ambiente indicado no programa, implantou a casa direito e, com estes vários croquis mostrando detalhes construtivos, você demonstra que pensa na construção desde o estudo preliminar do projeto". Acrescentou que, com o desenvolvimento posterior do projeto, eu poderia ir articulando melhor a volumetria até chegar ao resultado final. No entusiasmo da juventude, saí de lá dando pulos de alegria por ter conseguido o emprego. Muito tempo depois "caiu a ficha" sobre a profundidade 
dos comentários que meu contratante fez sobre o projetinho produzido por mim em umas cinco horas de trabalho. O tempo que passei no escritório, apesar de curto, foi importante para minha formação. Existia uma aura sobre o rigor da construção, de não se começar pela forma já feita do projeto, de procurar-se a melhor forma para cada parte estabelecida pelo programa de necessidades e inventar os detalhes para suas interfaces. Passei a conhecer melhor a obra dos arquitetos Alvar Aalto, Hans Scharoun, Louis Kahn e outros, dos quais pouco havia conhecido na FAUUSP. Anos depois, após passar algum tempo fora de São Paulo, com pouco contato intermediário, reencontrei o Guedes em nossa Escola. Nessas alturas eu já contava com alguns projetos realizados que ele conheceu. Resultou maior proximidade e passamos a compartilhar nossas aulas.

Como lembrança, acrescento ao texto uma foto com nossa turma de pósgraduação, uma foto do Guedes em cima do muro (verificando o terreno!).

\section{Adilson Costa Macedo}

Professor da FAUUSP

\section{Guedes, uma síntese}

O Guedes tinha, além das qualidades que Ihe são atribuídas - raciocínio lógico, velocidade e curiosidade - um espírito franciscano formidável, sobretudo se pensarmos a construção do país em suas várias escalas.

Anne Marie Sumner

Ex-orientanda

\section{No lugar de JOAquim guedes, O Lugar da ARQUITETURA}

Quando me pedem para escrever sobre o Guedes, encontro-me, justamente, substituindo-o em uma banca de concurso para novos professores do Departamento de Projetos da Escola de Arquitetura da UFMG. Dentre as citações e lembranças que o fazem reaparecer constantemente dentro de mim, repete-se o título de seu prefácio ao Eupalinos, de Paul Valéry: "Geometria habitada". Nesse título resume-se o encontro do espírito com a matéria e com a vida, a friç̧ão que institui a arquitetura e o urbanismo como fundadores do ser humano e da sociedade. Esse é o fundamento da paixão de Guedes pelos edifícios e cidades: eles são instauradores e reguladores da ação individual e coletiva, do sujeito e do cidadão, na história. A propensão polemista de Joaquim Guedes se alimenta do fato de 
também os edifícios e cidades de valor, como "os que falam" ou que "nos fazem dançar", na classificação de Eupalinos, só surgem mediante a faísca dos atritos produzidos e conflitos explicitados, a serem, com o tempo e o exercício, superados.

Os edifícios e cidades concebidos pelos arquitetos e urbanistas não são meros abrigos ou decorações da ação humana, mas estão na gênese dessa ação e de nosso contexto histórico e espacial. O espaço é fundamento e condição da história, e não seu mero invólucro. Poucos poderiam prefaciar o livro de Valéry, pois não saberiam compreender a disputa entre a labilidade das palavras e a habitabilidade concreta das construções, entre a frustração de Sócrates e a alegria de Eupalinos, relatada por Fedro ao seu mestre. Assim como a Guedes é estranho o arquiteto que se aliena devaneando formas aleatórias e fantásticas, não acompanhadas do modo com que seriam construídas e usadas, também não the parece plausível esse profissional conceber edifícios e cidades não-ancorados em meditação sobre a vida e diálogo com o tempo, com o lugar e a filosofia entendida como modo de ser e estar no mundo. Vivemos em uma dicotomia entre a contingência e o universal que cumpre à arte e à poesia rearticular. Também esse é o papel da arquitetura e do urbanismo, pontes lançadas entre as circunstâncias do presente e o desenho do homem e da sociedade que deveríamos ser. Vivemos uma época na qual forma e função, aparência e conteúdo, encontram-se rompidas: eis o que Guedes critica em alguns arquitetos, como Niemeyer. Também vivemos uma época de dicotomia entre o desenho, a economia e a construção: eis o que nosso arquiteto paulista denuncia na produção da arquitetura contemporânea e nos currículos universitários.

Empenhando-se em equilibrar os três componentes da tríade vitruviana - firmitas, utilitas e venustas - Joaquim Guedes se manteve, ao longo de sua trajetória profissional, intelectual e acadêmica, no epicentro da complexidade da arquitetura. Com veemência, ele se opunha a que ou a quem banalizava essa complexidade ou anulava qualquer uma daquelas componentes no exercício de sua reflexão, de seu discurso e de seu ofício.

Fazer arquitetura é muito difícil, quanto mais em uma época na qual ela reserva ao arquiteto quase apenas o trabalho de ornamentação do interior e do exterior de caixas predefinidas pelas imobiliárias, incorporadoras, construtoras ou grifes divulgadas na mídia ou em exposições. Tempo e árduo trabalho prático e intelectual são exigidos para que a arte de conceber e construir edifícios e cidades não se reduza ao irresponsável entretenimento lúdico, como em muitos pós-modernistas; ou aos delírios formais, como nas páginas da arquitetura contemporânea; ou à feitura de meros abrigos, mais ou menos sofisticados tecnologicamente, mas sem qualquer assento no espírito e no devir humano e social, como ele desconfiava entre os modernistas que the foram contemporâneos. Le Corbusier, inclusive. A teoria de Guedes, pois me agrada ultimamente considerá-lo como teórico e historiador, vigia-nos, hoje, quanto a esses desvios do tecnicismo, do pragmatismo e do formalismo vazios.

É a geometria que concede forma à matéria e à natureza brutas, despropositais, informes. Isso significa serem a arquitetura e o urbanismo antinaturais, imposição da ordem do pensamento e do afeto sobre a desordem, do projeto e fins humanos sobre a parte do humano que é alheio. Daí o caráter 
instaurador da obra do arquiteto: ele nos fornece o hábitat em que podemos desenvolver a "humanidade do homem" e o ambiente republicano, nos quais o bem comum e laico tem primazia sobre as idiossincrasias particulares, seja do cliente ou dos grupos sociais, seja do próprio arquiteto, do urbanista e das corporações, públicas e privadas. Em arquitetura, essa geometria não é para ser contemplada, ao contrário do modo com que a vê o mentor de Platão: ela é o lugar da ação individual e coletiva, no qual a idéia cai na história e deixa-se contaminar por nossas finitudes, possibilidades e fins mortais. Aristotélico e albertiano, Joaquim Guedes não vê nenhuma linhagem divina em nosso ofício, não o faz derivar de qualquer musa e inspiração, não lhe concede nenhuma parentesco de primeiro e segundo graus com as engenharias ou as chamadas belas artes. A arquitetura surge da reflexão metódica e crítica que se desenvolve em linhas, materiais e sistemas para ganhar corpo e compor o mundo no qual, efetivamente, habitamos e movemo-nos. Isso a torna, como confessa o próprio Sócrates, superior ao volátil universo das palavras e dos discursos retóricos.

Neste momento, agosto de 2008, Guedes conversa com Sócrates, Fedro e Eupalinos, sabe-se lá onde. Talvez preferisse continuar a conversa dominical mantida com o caseiro de sua fazenda, horas antes de ser estupidamente atropelado na avenida de uma coisa que não merece mais o nome de cidade, como também talvez não o mereça mais essa estrutura atendendo pelo nome de Belo Horizonte, na qual me alojo e desempenho minhas funções, como nesta banca, em que me sinto desconfortavelmente instalado, quase como um usurpador. Substituindo meu amigo paulistano, mantenho-o como referência crítica para avaliar os candidatos que ele julgaria com muito mais propriedade do que eu. Creio: o que ele mais avaliaria seria a quádrupla competência dialógica da arquitetura e do urbanismo: a) promover a interlocução entre o pensamento e a prática projetual e construtiva e entre o espírito e a matéria; b) cruzar a forma, o uso e as técnicas, pois é desse cruzamento que nasce a propriedade da arquitetura e seu insubstituível discurso; c) estabelecer a interlocução entre o projeto e o contexto espacial, histórico e social no qual a obra, ao ser introduzida, necessariamente deverá alterar; d) incitar o diálogo entre a arte de construir edifícios e cidades e a de prover a humanidade do homem e a república em que deve transcorrer a vida do indivíduo, da sociedade, da nação e do espírito.

Isso significa que a arquitetura e o urbanismo, bem como nossas outras produções técnicas e artísticas, não têm fins em si mesmos. Elas são apenas instrumentos da construção de uma vida melhor e mais justa, para a qual são tensionadas. Provavelmente, é esse o tema da conversa inquieta que Guedes mantém naquela região para aonde também esperamos ir. Nesta sala da Escola de Arquitetura em Belo Horizonte, de onde eu e Guedes já havíamos combinado sair para degustar uma comida mineira ou tomar um vinho e uma cachaça, tento encontrar, nas falas dos 18 candidatos que avalio, os vestígios e fragmentos que se harmonizam naquela conversa com que, nos ínferos, os dois filósofos e os dois arquitetos reordenam nosso mundo, medem nossas ações e riem de nossas vaidades e ilusões.

\section{Carlos Antônio Leite Brandão}

Professor da Escola de Arquitetura da UFMG 


\section{A CONTRibuiÇÃo de JOAquim GUedes À Arquitetura}

O trágico falecimento de Joaquim Guedes causou, como ele gostaria, uma série de polêmicas. Mas um ponto foi consensual entre todos: sua capacidade intelectual e produção arquitetônica foram marcantes no panorama cultural brasileiro.

Seu velório no saguão da Faculdade de Arquitetura e Urbanismo da Universidade de São Paulo foi visitado por vários de seus colegas e uma grande quantidade de ex-alunos, decorrentes de sua atuação como professor dessa instituição por quase toda a sua vida profissional. Essa homenagem feita pela FAUUSP corrige a ausência de homenagem, quando de sua aposentadoria, como professor titular, o primeiro professor titular de projeto oriundo da própria FAU.

Formado em 1954, orgulhava-se de uma de suas primeiras obras, a residência de seu pai, onde explorava com afinco o racionalismo dos espaços e da construção, para abrigar uma grande família. Nesse projeto já é possível captar a pesquisa de novas soluções arquitetônicas que marcaram toda a sua trajetória.

Já em 1955 projeta a igreja da Vila Madalena em São Paulo, uma obra que, apesar de muito descaracterizada atualmente, ainda expõe inovações da época, como o altar central, a expressão estrutural e o concreto aparente. Vale a pena salientar que essa foi uma das primeiras obras, se não a primeira, a explorar a linguagem do concreto aparente, característica marcante da produção paulista. Nesse projeto, o arquiteto Flavio Império desenvolve uma colaboração com Guedes, logo em seguida Sergio Ferro também colabora com Joaquim Guedes, ilustrando uma grande variedade de colaboradores, de grande competência e talento, os quais trabalharam em seu escritório, este a formar inúmeras gerações de profissionais.

A convivência em sociedade com Carlos Milan (1927-1964) foi muito importante para ambos. De um lado Milan, com sua influência inicial de formação mackenzista da arquitetura norte-americana, e, do outro lado, Guedes, no convívio com Vilanova Artigas e toda uma discussão de produção arquitetônica desse período.

É preciso destacar, dessa época, a produção do concurso de Brasília, e as casas D'Elboux, 1962 (Milan) e Cunha Lima, 1958 (Guedes), as quais, produzidas individualmente, explicitam a influência de cada um no trabalho do outro e a identidade que essas obras assumiram dentro do panorama da arquitetura brasileira. Guedes confidenciou que sua grande preocupação com o detalhe foi oriunda do convívio com Milan, do qual compartilhara muita amizade, tornando-se, os dois, compadres.

A Casa Cunha Lima mereceria um capítulo à parte em sua obra, pois ela marca uma nova linha de atuação com a estrutura explicitada de maneira bastante crua, aparente e inovadora. É uma das primeiras obras da produção apoiada em quatro pilares, solução que se tornou bastante usual na produção arquitetônica paulista. A melhor definição dessa obra foi dada pelo júri da premiação da VIII Bienal Internacional de Arquitetura de São Paulo, em sua justificativa do prêmio: "tudo (nessa obra) é verdade cruamente exposta, decorrente de uma série de razões materialmente precisas, logicamente encadeadas".

A influência de Le Corbusier em sua obra se dá, de maneira mais direta, no Fórum de Itapira (1959) e na Casa Costa Neto (1961), onde a cobertura de ambas traz uma releitura de Ronchamp, acentuando-se, principalmente, em sua produção de residências em abóbadas cerâmicas, nas quais novas soluções são buscadas, no 
sentido de explorar a linguagem do concreto e do tijolo cerâmico. Da Casa Costa Neto vale a pena salientar um exemplo de permanente pesquisa arquitetônica, com a solução dos caixilhos em montantes de concreto. A evolução disso ocorre na inserção do vidro temperado diretamente na estrutura ou na alvenaria, dando ao vidro, mesmo transparente, um importante papel na conformação volumétrica da arquitetura.

Essas soluções são exemplos de pesquisa construtiva realizada por Guedes, que, na seqüência de sua divulgação, foram incorporadas por várias gerações de arquitetos. Essa pesquisa também é resultado de sua primeira atividade didática na FAUUSP como professor de construção.

O afastamento da linha de Artigas se acentua em seu projeto para o Instituto de Matemática da USP (1963), o qual, não-construído, marcava uma nova fase, com influência da produção aaltiana.

A residência Francisco Landi (1965), detentora do 1o Prêmio Governador do Estado, no XVII Salão Paulista de arte Moderna de 1968, expõe melhor essa nova visão da arquitetura, com uma residência em tijolo cerâmico e estrutura em pórticos de concreto aparentes, além de cobertura em telha ondulada de fibrocimento. Essa casa denota uma nova visão dentro da produção arquitetônica paulista e brasileira, e explicita, mais uma vez, a preocupação de Guedes com o sistema construtivo e a racionalidade da construção. Toda a casa foi modulada na dimensão da telha ondulada, para permitir um correto arremate da telha com seus beirais e a estrutura de concreto.

A residência Perseu Pereira (1967) radicaliza a influência de Aalto com uma obra a utilizar-se da forma de maneira bastante racional, sem perda do rigor lógico quanto à sua organização e construção, conforme a definição do júri que the outorgou o Prêmio Rino Levi do IAB-SP.

A Residência Liliana Guedes (1968) no Morumbi, em São Paulo, retoma a linguagem dos quatro pilares e da forma pura, quebrada por amplas abas de concreto que a protegem da insolação, transformando o estar em amplo terraço. Novamente a racionalização da construção se explicita com a estrutura toda modulada na dimensão da forma de madeirite, para se evitar perdas de material.

Seus trabalhos de urbanismo são um retrato da produção de arquiteto em suas edificações. Para ele, a citação "a casa como cidade, a cidade como casa" era mais do que verdadeira, tanto que não admitia o termo urbanista junto do título de arquiteto. Para ele, o urbanismo era algo inerente ao arquiteto e não podia ser dissociado.

Dentre suas produções urbanas, destaca-se Caraíba, no interior da Bahia, na qual todos os desenhos da cidade e das construções foram criados por Guedes e sua equipe, resultado de uma rigorosa pesquisa de campo e da racionalização dos espaços, da construção e dos materiais. Nesse processo do projeto de Caraíba, Guedes levou ao extremo a racionalização da construção, aplicando-a ao próprio processo projetual, em que os desenhos do projeto executivo eram agrupados por categorias de serviço na obra (alvenaria, estrutura, caixilhos, acabamentos) e, para cada categoria, era produzido um desenho no qual constavam somente as informações necessárias a essa etapa de trabalho, buscando, com isso, uma melhor organização das fases da obra.

Nas residências Beer (1975) e Mariani (1978), a linguagem do tijolo aparente é retomada de maneira diferente, até mesmo como revestimento da estrutura, 
explorada e explicitada, com um desenho diferenciado do tijolo, denotando a verdade estrutural, mesmo quando revestida. Nessas obras, já se aponta sua visão crítica ao uso indiscriminado do concreto aparente pela arquitetura paulista e brasileira.

Sua proposta para a recuperação do Tuca, Teatro da PUC-SP, finalizado em meados dos anos 90, Guedes busca, com a racionalidade da proposta, recuperar a história desse importante espaço cultural. As paredes queimadas, deixadas aparentes, refletem que mesmo dentro de seu radicalismo construtivo há espaços para poéticas a marcarem a arquitetura.

Intervenção como essa no Tuca também ilustra um vasto campo de atuação de Guedes em edificações existentes, dando-Ihe nova identidade. Importantes espaços em São Paulo tiveram propostas de Guedes, como o Teatro Oficina, o Hotel Jandaia, o João Sebastião Bar, além de várias residências, transformando esses espaços em pontos marcantes da produção arquitetônica.

Mais recentemente sua produção havia se reduzido, mas mesmo assim ainda é possível observar sua permanente insatisfação e labuta com a arquitetura, buscando sempre inovação e pesquisa, como a realizada no Pavilhão de Lazer no Jardim Botânico-RJ (1996), onde o sistema construtivo em madeira foi o objeto de trabalho.

Esse rápido relato de seu percurso é necessário para ilustrar sua personalidade. Suas posições eram radicais. Suas idéias eram, para ele, as corretas. Defendia suas posições com extremo rigor, o que levava a angariar cada vez mais uma grande corrente de opositores e até inimigos. Defendia seus projetos com vigor, o que levava a um difícil relacionamento com seus clientes, mas o resultado final poderia até justificar tal situação, se não fosse o grande sofrimento do processo.

Sua preocupação com o detalhe e a verdade dos materiais era o que valorizava sua produção. Muitas vezes, seus projetos próximos à finalização eram repensados na busca de uma melhor solução, a exigir toda uma retomada de etapas vencidas, e, eventualmente, até um prejuízo financeiro, na busca de um resultado melhor, o qual, invariavelmente, era alcançado, após muitos desgastes, ilustrando bem seu processo doloroso de criação.

A personalidade de Joaquim Guedes dentro do panorama da arquitetura brasileira era muito marcante e importante, não somente por sua produção arquitetônica, mas, principalmente, por ser uma voz destoante, que expressava coerentemente suas idéias e representava uma boa parcela da visão arquitetônica brasileira, a qual não se enxergava na produção corrente.

Sua licença do IAB-SP para concorrer ao cargo de vereador na cidade de São Paulo, após a grave situação política criada na entidade, inclusive com decisão definitiva de posse a ser dada ainda pela justiça, servem, ao mesmo tempo, para ilustrar sua participação nesse processo e sua eterna busca por uma nova luta e ideais, com espírito jovem e aguerrido.

De qualquer maneira, Joaquim Guedes será lembrado e reconhecido por sua importante produção arquitetônica e intelectual dentro do quadro da arquitetura brasileira, e sua personalidade forte e marcante, deixando discípulos e seguidores, como uma importante contribuição à cultura e arquitetura brasileiras, reconhecida até mesmo por seus opositores.

\section{Gilberto Belleza}

Ex-orientando 


\section{O QUE APRENDI COM JOAQUIM GUEDES}

Convivi com Joaquim Guedes por quase dez anos, durante minha permanência no Programa da Pós-Graduação da FAU. Com ele tive o privilégio de vivenciar gratificantes "lições de arquitetura": como aprendiz, ouvia atentamente aulas sobre edifícios, cidades, praças. "É preciso imaginar o objeto e inventar sua construção!", dizia com entusiasmo. Mas foi desvendando São Paulo que compreendi: mesmo acostumado à convivência com múltiplas culturas pelo Brasil e exterior, sua paixão era a cidade onde nasceu, e pela qual trabalhou incansavelmente para torná-la melhor. "São Paulo é fantástica!", repetia.

Quando propus trabalhar com moradias assistidas para idosos, perguntou-me, sarcástico: "Você vai desenvolver projetos de casas para velhos? O que as torna diferentes de quaisquer outras com boa arquitetura?" Aceitou o desafio, constantemente criticando duramente minhas posições, e fomos construindo um caminho baseado na metodologia de projeto para garantir essa boa arquitetura. Discutíamos lugar, usuário e sustentabilidade. Eu, preocupada em definir necessidades e desejos dos idosos, ele, exigindo minha atenção para os meios de invenção do objeto.

"Como se atreve a discordar de seu orientador?" dizia, sorrindo. No prefácio de Eupalinos ou o arquiteto, de Paul Valéry, Guedes diz: "Quem copia não sabe nada, por isso aluno não tem guru. Tem que ser voraz e rebelde. Tem que negar os mestres. Tem que amá-los, ouvi-los, sugá-los e destruí-los dentro de si, para aprender a construir seu caminho..." Fui provocada a argumentar, refletir, revisar posições: ele foi generoso ao permitir que fossem esgotadas todas as dúvidas. Oferecia-me o desafio, apoiando minhas reflexões com leituras fundamentais e discussões que superassem os preconceitos, garantindo meu amadurecimento.

Guedes permanece vivo por ter provocado tanto, e ele não desaparece porque ainda temos muito o que aprender com sua extensa produção. Certamente, as gerações futuras de jovens arquitetos vão admirá-lo como fazemos hoje, pois sua obra permanecerá viva e instigante tal como conhecemos. Sentimos falta de seus argumentos e provocações ferinas, expressões da sua combatividade, mas somos todos, como admiradores, capazes de continuar a mantê-lo aqui, fazendo a diferença.

\section{Maria Luisa Trindade Bestetti Ex-orientanda}




\section{GuEdes - QuANDO CESSA O PENSAMENTO}

"Pra que partir, se em toda parte é o fim do mundo?" diria Cioran, o filósofo pessimista, ou se escutaria a sentença inexorável do inspirado Fernando Pessoa:

"A morte chega cedo,

Pois breve é toda a vida

0 instante é o arremedo

De uma coisa perdida."

Foi inesperada essa partida. Eu, que o imaginava ainda em Lisboa ou Madri, conforme planejara, eis que o sinto reduzido a uma lacônica notícia telefônica: "O Joaquim Guedes morreu, tragicamente, atropelado". Meu relógio marcava meia-noite, fim do dia 27 de julho de 2008. Fim da vida de um grande amigo, encontro trágico dos dois ponteiros de um relógio que parou. A vida e a morte se despedem. E o pensamento cessa.

Havíamos estado juntos, há pouco tempo, em Torino, Itália, como membros da delegação oficial do IAB, no XXIII Congresso Mundial de Arquitetos. Foram dez dias de convivência, durante esse longo evento, o congresso e, depois, a Assembléia Internacional. Além dos contatos cotidianos, os 11 membros da delegação realizaram várias reuniões, para troca de idéias e fixação de estratégias.

Percebi algo de estranho no olhar do companheiro. Eu não conseguia distinguir, nesse olhar, a fronteira entre o cansaço e a tristeza. Seu dinamismo próprio e polêmico guardavam escala modesta. Seria essa uma premonição? Não sei. Mas posso afirmar que o velho companheiro não morreu feliz.

Fomos amigos, ao longo de 40 anos, e foi-me possível conhecê-lo muito bem. Durante esse período de tempo fomos sócios por sete anos (Guedes, eu, Paulo Guedes, Hiroo Nanjo, Luiz Manini) - 1981- 1988; convivemos longos anos na FAUUSP, no exercício da docência, e ao longo de nossa militância, no IAB.

As histórias são muitas, e muitas foram as refregas, as discussões, as parcerias, dissensões, conferências, seminários, congressos, eventos compartilhados. Todos esses são fatores que nos ajudam na formação do processo cumulativo, fixando, na memória, as glórias e os infortúnios.

Guedes sempre cultivou os atributos do pensamento dialético, mesmo, por vezes, precisando enfrentar dificuldades ao detalhar os limites do contraditório. Cultivou as artes, a música, o teatro, a literatura, a filosofia, as tecnologias e a arquitetura, sempre aberto às alegrias e aos percalços do novo. Com esses valores, moldou o cotidiano de suas preocupações, suas amizades, seus afetos e suas paixões profissionais. Nunca economizou o sorriso nem a gentileza, mesmo que tivesse de desenhar, na face, os momentos de contrariedade, com seu característico sobrolho contraído.

Sua ambição era justa, condizente com a escala de seu talento e de sua competência: uma obra vasta e de pleno reconhecimento. Nem tudo o que quis, conseguiu. Levou consigo a mágoa da contrariedade e da mesquinhez do mercado de trabalho, raramente pautado pela qualidade e por valores culturais. Soube construir sua segura visão do mundo da arquitetura e seus discursos próprios, perspicazes e polêmicos. A arquitetura expressou-a, 
sempre, pela racionalidade madura de seu método de trabalho, perseguindo a forma, a excelência tecnológica, a concretude daquilo que era possível e, afinal, a beleza. Sua linguagem expressiva não seguiu os cânones dos postulados racionalistas de Le Corbusier. O mestre finlandês, Alvar Aalto, foi seu grande inspirador. Porém, o Brasil vivia a ciranda das glórias da escola corbusiana. Em um mundo que não professava a cultura da pluralidade, sobrou-lhe a alcunha perversa de "alienígena", pela ousadia de tal procedimento. Não se pode negar que Guedes tenha sido um contraponto na esteira do movimento moderno da arquitetura brasileira, a escala justa da necessidade do contraditório, alimentadora de um debate o qual nunca existiu, no Brasil. Assim, também foi a abstinência brasileira em relação à linguagem pós- moderna. As escolas de arquitetura e os arquitetos foram privados da discussão do que acontecia no resto do mundo.

Guedes viveu, no mais alto nível, o exercício da docência. Reconhecido, nesse mister, plenamente, por alunos e professores. Era mestre de uma implacável disciplina de trabalho, em cobrança superlativa, sem qualquer tipo de concessão em relação aos maus hábitos do projeto sem qualidade. Uma penitência admissível, um ganho inquestionável, sempre admitido e reconhecido pelos alunos.

O discurso irreverente e polêmico, no relacionamento cotidiano da prática profissional, recolhe-se nas pausas do trabalho intelectual, para dar lugar ao nascimento de textos cuidadosamente elaborados, registrando contribuições valiosas. Esses textos, sem qualquer dúvida, merecem ser organizados sob a forma de livro. O escasso discurso da arquitetura brasileira e, igualmente, o raro discurso dos "arquitetos-de-prancheta", necessitam do conjunto dessas reflexões.

Guedes não foi um "campeão", porque, como os bons atletas, não teve sorte em alguns setores da frente de batalha, dentre eles, o da política profissional. Queria ser presidente do IAB de São Paulo, queria ser vereador, e, também, presidente do IAB nacional. Buscava, com isso, nessa faixa de poder, a democratização do mercado de trabalho para os arquitetos.

Por fim, o velho timoneiro contrariou o caminho dos automóveis e foi colhido de surpresa, não teve tempo de racionalizar esse incidente. Não teve tempo de planejar a partida, nessa hora em que cessa o pensamento.

Guedes não teve tempo de concluir sua obra, porque "a morte chegou cedo".

\section{Miguel Pereira}

Professor da FAUUSP 
(1) GUEDES SOBRINHO, Joaquim. Memorial para o concurso para provimento de um cargo de professor titular junto ao departamento de projeto, grupo de disciplinas de projeto de edificações. São Paulo: FAUUSP, 1987. p. 18.

(2) GUEDES SOBRINHO, Joaquim. Ajuste conceitual da formação do arquiteto. Sinopses, São Paulo, p. 51, n. 19, jun. 1993.

\section{UM GRANDE MESTRE: JOAQUIM GUEDES}

Joaquim Guedes formou muitas gerações de arquitetos; nem todos conseguiram usufruir seu vasto potencial, mas aqueles que dele se aproximaram são profundamente reconhecidos da importância do mestre em suas trajetórias. Possuía a correta dimensão de seu papel de educador e do papel da universidade no desenvolvimento técnico-científico para o progresso social. Gostava da interlocução, tinha prazer em ensinar, vocação para professor. Só não aprendeu com ele quem não se dispôs a compreendê-lo. Qualquer conversa de corredor transformava-se rapidamente em grande aula, explicava com paciência seus projetos, suas idéias. Entrou para a docência em 1958, com apenas quatro anos de formado, como assistente na cadeira de Material de Construção, percorrendo, posteriormente, as disciplinas de Planejamento e Projeto, com as quais se aposentou como professor titular.

Ter iniciado sua vida acadêmica na disciplina de Materiais e Técnicas facilitou-Ihe a aproximação das questões mais práticas da arquitetura, proporcionando-Ihe um conhecimento que, segundo ele, foi decisivo no desenvolvimento de sua carreira: "Estudei o concreto, o tijolo e o vidro. Os alunos e eu estudamos; visitamos indústrias de materiais e obras. Cheguei nesse período a fazer projetos experimentais e detalhes que talvez não tivesse feito da mesma maneira se não tivesse tido a oportunidade de pertencer à cadeira de Materiais de Construção, a série de casa de abóbadas, as experiências pioneiras de vidro temperado aplicado diretamente no concreto aparente mediante um tipo de detalhe especial, sem caixilhos, que abriu todo um novo campo formal." "Essa sua experiência permitiu-Ihe projetar, com precisão e segurança, obras sólidas, racionais e inovadoras.

Guedes conseguiu estabelecer uma profícua relação entre suas atividades. Muitos de seus projetos foram realizados com o claro objetivo didático de expor a necessidade de criar, baseada em princípios que pudessem ser facilmente percebidos e reproduzidos, e pelos quais acreditava ser possível desenvolver a personalidade individual de cada aluno. O caminho intelectual do aluno era seu alvo de ação. Para ele, a docência consistia em fazer o aluno perceber seu papel na produção da arquitetura, por meio da busca de sua poética pessoal. "Formar arquitetos para a sociedade de nosso tempo, implica um sistema pedagógico fundado em referenciais objetivos que os comprometam com aspectos vivos e mais humanos do desenvolvimento da sociedade." 2

Além do mestre e colega, perdi um grande amigo.

\section{Mônica Junqueira de Camargo} Professora da FAUUSP 


\section{JOAQUIM GUEDES: ARQUITETURA E MEDITAÇÃO}

"Geometria habitada" é o prólogo de Joaquim Guedes para Eupalinos ou o arquiteto, de Paul Valéry. É um discurso do método e uma filosofia da construção. Conjugando a utilidade das edificações e a arte do bem viver, a geometria de Guedes é a forma da matéria, é sua alma. Como Giotto traçando um círculo perfeito sem régua ou compasso, o rigor não é, aqui, o do espírito geométrico, mas o espírito de geômetra.

Crítico da arquitetura como tarefa de engenharia, crítico da arquitetura como forma pura, crítico de quem se perde "em desenhos exploratórios do nada", Guedes não acreditava na "arte pela arte". Para ele, os constrangimentos de ordem prática - das condições econômicas e sociais às ambientais e técnicas - não manifestam nossa limitação e finitude, mas nossa liberdade.

Sua arquitetura contém todas as artes, ela é a ciência primeira, sua física e sua metafísica: "a casa é a primeira construção e [...] constrói o homem. A casa é seu corpo, que é a medida do mundo, dá as verdadeiras referências do prazer e guia o espírito." Não por acaso a epígrafe de sua apresentação revela um pensamento para o qual "a physis é o logos". Por isso, Guedes não esquadrinha planos para medir distâncias, tudo reduzido a linhas ortogonais que tolhem o movimento e fixam o espaço.

A linha de suas construções assemelha-se à da geometria de um Platão, ela procura o mais alto, o mais elevado. Mas o sublime não é uma "idéia inexprimível da imaginação", porque a arquitetura de Guedes tudo reúne no halo de uma elegância que se ordena. Sua geometria contém uma experiência de "criação do mundo".

O prefácio a Eupalinos manifesta um pensador insurgente, avesso a consensos e adesões. Nele está presente, por inteiro, o arquiteto, o professor, o escritor, o amigo. É uma aula magistral de arquitetura e vida. Para Guedes vale a máxima com a qual finaliza seu ensaio: "Extraordinários ensinamentos [os de Eupalinos], ensinamentos de uma curta e interrompida lição."

\section{Olgária Matos}

Professora do Departamento de Filosofia da USP 


\section{JoAquim GUEDES}

Não está mais conosco o arquiteto e grande mestre Joaquim Guedes, que desenvolveu projetos de excepcional qualidade e relevância internacional. Dedicou boa parte de sua vida à FAUUSP, onde se aposentou como chefe do Departamento de Projeto.

O título de sua tese de livre-docência, Um projeto e seus caminhos, revela sua preocupação pedagógica com o fazer, os percursos e possibilidades de organização da forma, sempre considerando em profundidade "o sítio, o cliente e as tecnologias disponíveis".

Tive o prazer de poder participar de alguns projetos de seu escritório: do concurso para o Centro Cultural de Belém-Lisboa, do projeto da residência Franco Neto em Tijucopava, do projeto para o SESI de Mogi-Guaçu e, por último, do projeto para o Centro Integrado de Abastecimento de São Paulo CIASP, o qual obteve prêmio do IAB-SP em 2002.

A partir do projeto para o concurso do Centro Cultural de Lisboa, freqüentemente citado em suas conversas, e apoiado nas experiências de Caraíba e no trabalho com o Padre L. Lebret, passa a enfatizar a utilização dos diagramas no desenvolvimento dos projetos, relacionando as formas à vida da sociedade e da cidade.

Solitário muitas vezes na defesa de suas convicções, em sua postura correta e rigorosa, buscava uma arquitetura mais justa. Não se calava enquanto crítico responsável e rigoroso da sociedade e da arquitetura.

Orientou dezenas de dissertações de mestrado e teses de doutorado, sempre generoso ao partilhar seu conhecimento e abrir espaço em sua agenda invariavelmente repleta de atividades. Durante suas orientações, nossas conversas eram longas e a leitura das linhas escritas um esforço incrível para encaminhar idéias sem, contudo, impor seus próprios pensamentos. Em seu escritório, o trabalho não era muito diferente - cada detalhe, cada decisão exigia muitas horas de sua reflexão, investigação atenta e produção de muitos desenhos.

Apaixonado pela vida, encantava-se com as realizações humanas. Viveu de maneira intensa.

\section{Paula Katakura}

Ex-orientanda 